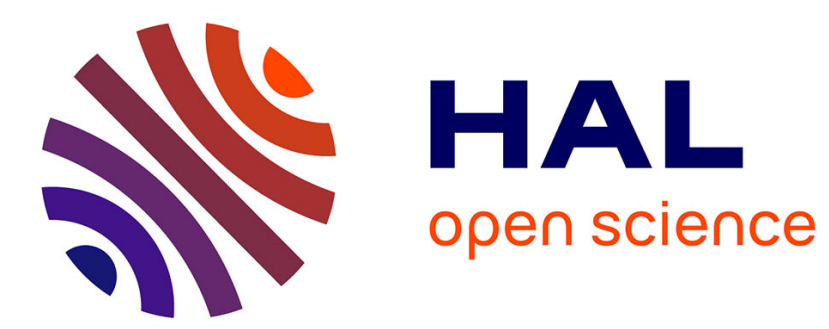

\title{
Measurements of the write error rate in bit patterned magnetic recording at $100-320 \mathrm{~Gb} /$ in 2
}

M Grobis, E Dobisz, O Hellwig, M.E. Schabes, G Zeltzer, Thomas Hauet, T.R. Albrecht

\section{- To cite this version:}

M Grobis, E Dobisz, O Hellwig, M.E. Schabes, G Zeltzer, et al.. Measurements of the write error rate in bit patterned magnetic recording at 100-320 Gb/ in 2. Applied Physics Letters, 2010, 10.1063/1.3304166 . hal-01345340

\author{
HAL Id: hal-01345340 \\ https://hal.science/hal-01345340
}

Submitted on 18 Jul 2016

HAL is a multi-disciplinary open access archive for the deposit and dissemination of scientific research documents, whether they are published or not. The documents may come from teaching and research institutions in France or abroad, or from public or private research centers.
L'archive ouverte pluridisciplinaire HAL, est destinée au dépôt et à la diffusion de documents scientifiques de niveau recherche, publiés ou non, émanant des établissements d'enseignement et de recherche français ou étrangers, des laboratoires publics ou privés. 


\title{
Measurements of the write error rate in bit patterned magnetic recording at $100-320 \mathrm{~Gb} / \mathrm{in}^{2}$
}

\author{
M. Grobis, ${ }^{\text {a) }}$ E. Dobisz, O. Hellwig, M. E. Schabes, G. Zeltzer, T. Hauet, and T. R. Albrecht \\ San Jose Research Center, Hitachi Global Storage Technologies, 3403 Yerba Buena Rd., San Jose, \\ California 95135, USA
}

(Received 4 December 2009; accepted 12 January 2010; published online 4 February 2010)

\begin{abstract}
We demonstrate a technique for measuring the intrinsic bit-error-rate as a function of write misregistration in bit patterned media. We examine the recording performance at bit densities of 100, 200, and 320 Gigabits per square inch $\left(\mathrm{Gb} / \mathrm{in}^{2}\right)$ and find that the on-track write misregistration margin for error rates below $10^{-4}$ is $\sim 1 / 4$ of a bit length for all three densities. We demonstrate two-dimensional recording at sub $10^{-4}$ bit error rate at 100 and $200 \mathrm{~Gb} / \mathrm{in}^{2}$ and with a $10^{-3}$ bit error rate at $320 \mathrm{~Gb} / \mathrm{in}^{2}$. (C) 2010 American Institute of Physics. [doi:10.1063/1.3304166]
\end{abstract}

Storage density in conventional hard drive media is limited by the balance of low media noise, thermal stability, and write-ability. Patterning the media into arrays of single-grain magnetic islands provides one possible way to extend the balancing act to storage densities of $1 \mathrm{~Tb} / \mathrm{in}^{2}$ and beyond. ${ }^{1,2}$ Bit patterned media (BPM), however, adds the complication of needing to synchronize the write process with the physical locations of the patterned bits. Due to the finite magnetic field gradients of the write head and the spread in switching fields for the islands, the write error rate depends sensitively on the spatial alignment between the write field transitions and the bit locations. ${ }^{2-4}$ Since written-in errors rather than read-back errors are the dominant contribution to the overall bit-error-rate (BER) in $\mathrm{BPM}^{2}$ the dependence of the write error rate on write misregistration is a determining factor for evaluating BPM in magnetic recording applications.

Measuring intrinsic bit error rates in BPM using conventional magnetic recording equipment is challenging because stable write synchronization, track following, and head-disk separation can be difficult to achieve on bit patterned disks. ${ }^{5,6}$ While these difficulties must be overcome for BPM to be technologically useful, they complicate the quantitative characterization of the intrinsic capabilities of a BPM recording system. Previous magnetic recording work has demonstrated reading and writing on BPM at a variety of densities ${ }^{3,5,7}$ but the recording performance at error rate levels of practical importance to magnetic data storage has been unexplored. In addition, the link between recording performance and the physical properties of the head-media system has not been experimentally demonstrated.

In this letter, we present a method for measuring the intrinsic written-in BER as a function of write misregistration in BPM. The technique relies on measuring the downtrack and cross-track registration throughout the writing process and using that information to classify write errors as they arise. We use our technique to measure the write performance of BPM media at 100,200 , and $320 \mathrm{~Gb} / \mathrm{in}^{2}$, with track (bit) pitches of $130 \mathrm{~nm}(50 \mathrm{~nm}), 80 \mathrm{~nm}(40 \mathrm{~nm})$, and 50 $\mathrm{nm}(40 \mathrm{~nm})$, respectively. We find that all patterns support a sub $10^{-4}$ on-track error rate (OTER) with a down-track misregistration margin of around $\pm 1 / 4$ bit length. The OTER behavior is in excellent agreement with the measured media

${ }^{\text {a)} E l e c t r o n i c ~ m a i l: ~ m i c h a e l . g r o b i s @ ~ h i t a c h i g s t . c o m . ~}$ properties and expected write fields. At $100 \mathrm{~Gb} / \mathrm{in}^{2}$ the adjacent track write rate (ATWR) is negligible and we demonstrate two-dimensional recording at an overall BER (ATWR+OTER) below $10^{-4}$. The track pitches at 200 and $320 \mathrm{~Gb} /$ in $^{2}$ are narrower than the write width of our recording head. Using shingled magnetic recording ${ }^{8}$ we demonstrate a sub $10^{-4} \mathrm{BER}$ at $200 \mathrm{~Gb} / \mathrm{in}^{2}$ and a $10^{-3} \mathrm{BER}$ at $320 \mathrm{~Gb} / \mathrm{in}^{2}$.

The magnetic islands in our experiment were fabricated by etching an e-beam defined pattern into a silicon nitride film deposited on top of a soft magnetic underlayer and etch stop layer. Magnetic multilayer material with composition $\mathrm{Ta}(15 \AA) \operatorname{Pd}(30 \AA)[\mathrm{Co}(2.8 \AA) \operatorname{Pd}(9 \AA)]_{6} \mathrm{Pd}(5 \AA) \operatorname{Co}(2.8 \AA)$ $\times[\mathrm{Ni}(6 \AA) \mathrm{Co}(1.5 \AA)]_{2} \mathrm{Co}(1.3 \AA) \operatorname{Pd}(20 \AA)$ was deposited subsequently on top of the etched patterns. ${ }^{9,10}$ Overcoat and lube were deposited on top of the magnetic material prior to testing. The patterned island aspect ratios were $2.6,2.25$, and 1.25 and coercivities were $6.5,6.9$, and $7.5 \mathrm{kOe}$ for the 100 , 200, and $320 \mathrm{~Gb} / \mathrm{in}^{2}$ patterns, respectively. All three patterns had one sigma switching field distributions of $1.0 \mathrm{kOe}$. The recording measurements were performed using a static tester in which the read-write head was in direct contact with the disk during reading and writing. ${ }^{11}$ The static tester setup allows stable reading and writing of magnetic patterns without the additional overhead of the complex servo scheme required by conventional testers, though at scan speeds less than $100 \mathrm{um} / \mathrm{s}$. Heads from commercially available hard disk drives (HDD) were used to read and write the patterned media. The heads had a mean write width (MWW) of $\sim 85 \mathrm{~nm}$ as determined by the full-width half-max of the track averaged signal amplitude on conventional HDD media under write conditions equivalent to the BPM experiment, $8-10 \mu$ s write pulse per bit.

The patterned region on our disks contains two main parts - a data storage region and a servo region as shown in Fig. 1. For our experiment the servo and data regions are each $\sim 10 \mu \mathrm{m}$ long in the down-track direction. The servo region is dc magnetized and the servo information is encoded by the magnetic contrast difference between the patterned islands and recessed trenches. The servo region consists of synchronization marks that run in the cross-track direction and cross-track position marks that run at a skew angle to the track. The synchronization and position marks have different spatial frequencies in the down-track direction. Due to the 


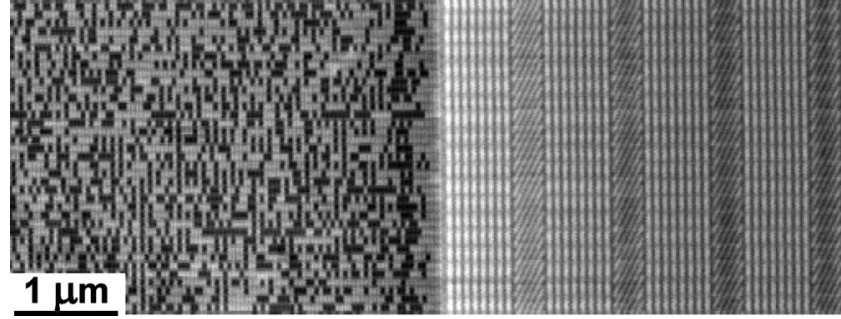

FIG. 1. Magnetic read-back image at $200 \mathrm{~Gb} / \mathrm{in}^{2}$ showing the data and servo fields. The data is randomly magnetized while the servo region is dc magnetized.

fixed 6-8 $\mu \mathrm{m}$ down-track separation between the read and write elements, a portion of the servo region can be read during the write process. The two key parameters extracted from the servo are the phase difference between the write clock and the synchronization marks $\left(\varphi_{\mathrm{w}}\right)$ and the cross-track position. The two parameters are used for feedback control of the head position and for compiling the OTER and ATWR by $\varphi_{\mathrm{w}}$ and track offset.

The OTER versus write phase $\left(\varphi_{\mathrm{w}}\right)$ curves for the $100-320 \mathrm{~Gb} / \mathrm{in}^{2}$ patterns are shown in Fig. 2. $\varphi_{\mathrm{w}}$ is normalized by the bit pitch so that increasing $\varphi_{\mathrm{w}}$ by 0.25 is equivalent to shifting the write current waveform by 0.25 of a bit in the down track direction. The curves are shifted so that the maximum error rate when writing on track center occurs at $\varphi_{\mathrm{w}}= \pm 0.5$. The curves were compiled by writing pseudorandom data to a block of 100 different tracks, each consisting of 100-200 bits. To acquire the necessary statistics the pro-

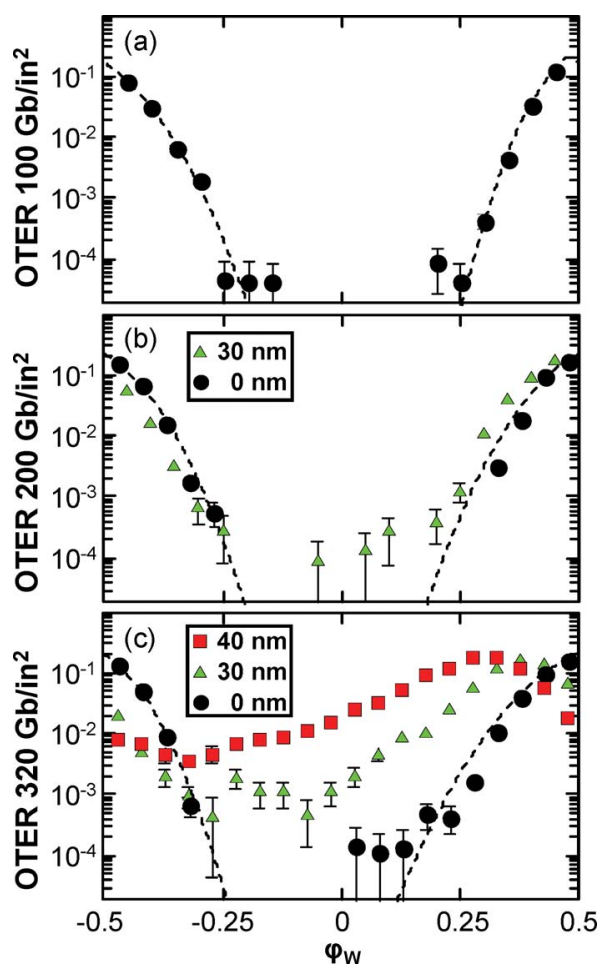

FIG. 2. (Color online) OTER vs write phase and track write offset for (a) $100 \mathrm{~Gb} / \mathrm{in}^{2}$, (b) $200 \mathrm{~Gb} / \mathrm{in}^{2}$, and (c) $300 \mathrm{~Gb} / \mathrm{in}^{2}$. The write phase is normalized by the bit length and the data is parsed in 0.05 bit intervals. A lack of data points indicates that no errors were recorded when writing at the specified write phase. The error bars represent 1-sigma statistical uncertainty. The dotted lines are fits of the OTER at zero track offset using Eq. (1). The shifting of the OTER curves with track offset originates from the curvature of the head fields at the edge of the writer.

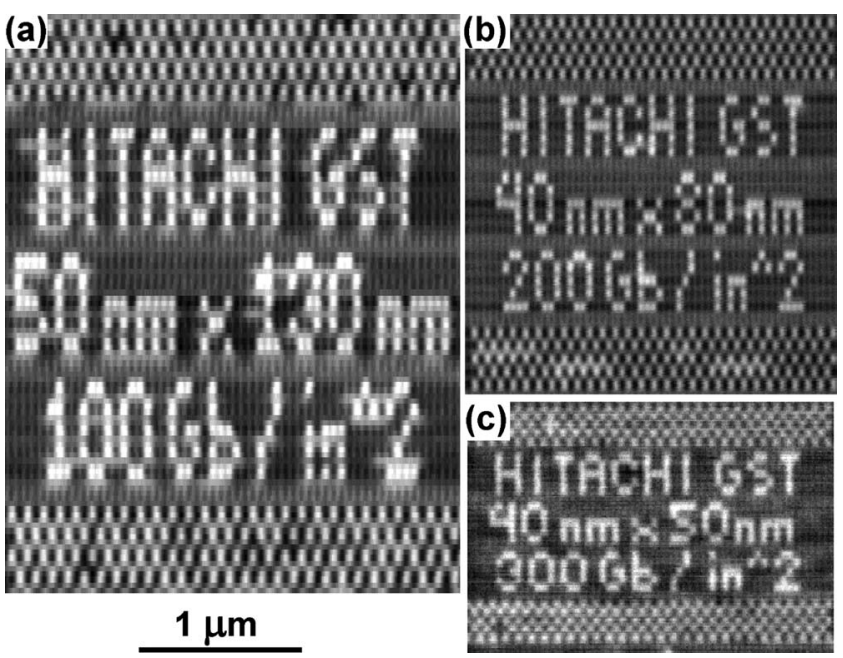

FIG. 3. Magnetic read-back image showing patterns consisting of $\sim 2000$ bits written at (a) $100 \mathrm{~Gb} / \mathrm{in}^{2}$, (b) $200 \mathrm{~Gb} / \mathrm{in}^{2}$, and (c) $320 \mathrm{~Gb} / \mathrm{in}^{2}$. The blurred features seen in between the island signal in $[(\mathrm{a})$ and (b)] originates from trench domains (Ref. 10).

cess was repeated up to 30 times with different write phases and data sequences. $\varphi_{\mathrm{w}}$ for each written bit was determined by fitting the simultaneously acquired synchronization readback signal with a single frequency and phase. As seen in Fig. 2(a) the OTER for the $100 \mathrm{~Gb} / \mathrm{in}^{2}$ pattern falls below $10^{-4}$ for $-0.25 \leq \varphi_{\mathrm{w}} \leq 0.25$. No adjacent track errors were recorded when writing within $2.5 \mathrm{~nm}$ from track center, indicating that the ATWR is below $10^{-5}$. The OTER curves when writing on track center for the 200 and $320 \mathrm{~Gb} / \mathrm{in}^{2}$ patterns [Figs. 2(b) and 2(c)] are similar to the $100 \mathrm{~Gb} / \mathrm{in}^{2}$ curve. However, the ATWR under this writing condition is $\sim 0.4$ for the $200 \mathrm{~Gb} / \mathrm{in}^{2}$ and $\sim 1$ for $320 \mathrm{~Gb} / \mathrm{in}^{2}$. The ATWR is normalized by the number of bits written on the target track, meaning that an ATWR of 1 corresponds to the head writing three tracks simultaneously. The wide writing is not surprising since the MWW of the head is $85 \mathrm{~nm}$ on conventional media.

Given the wide write width of the head, we explored the BER performance capability of the 200 and $320 \mathrm{~Gb} /$ in $^{2}$ patterns using shingled magnetic recording. ${ }^{8}$ When shingling, the center of the write head is offset from the center of the target track and we denote this difference as the track write offset. To separate the effects of on-track writing performance and adjacent track writing we measured the OTER on the target track before shingling the next track. The ATWR represents the bit flip rate on the previously written track. Writing at $200 \mathrm{~Gb} / \mathrm{in}^{2}$ with a $30 \mathrm{~nm}$ track write offset increases the OTER floor to $\sim 10^{-4}$ [Fig. 2(b)] but reduces the ATWR below $10^{-5}$. At $320 \mathrm{~Gb} / \mathrm{in}^{2}$ the OTER curves degrade as the track write offset is increased from 0 to $40 \mathrm{~nm}$ [Fig. 3(b)]. The best combined BER of $\sim 10^{-3}$ is achieved at $30 \mathrm{~nm}$, where the OTER and ATWR are both $(1 \pm 0.5)$ $\times 10^{-3}$. The ATWR continues to decrease by an order of magnitude per $10 \mathrm{~nm}$ of track write offset, but the worsening down-track gradients at the edges of the writer limit the overall BER performance. Figure 3 shows a demonstration of the two-dimensional read-write performance that can be achieved for the $100-320 \mathrm{~Gb} / \mathrm{in}^{2}$ patterns studied in the paper. The bit pattern consists of $\sim 2000$ bits and was recorded with zero errors for 100 and $200 \mathrm{~Gb} / \mathrm{in}^{2}$, and two errors at $320 \mathrm{~Gb} / \mathrm{in}^{2}$. 
The OTER curves on track center can be fit using a simple model in which errors occur if (1) the head field is large enough to flip previously written bits or if (2) the head field is too small to write the bit at the effective write edge. ${ }^{2}$ The OTER is described approximately by:

$$
\begin{aligned}
\operatorname{BER}\left(\varphi_{w}\right)= & 2 \times E_{0}\left\{1+\frac{1}{2}\left[\operatorname{erf}\left(-\frac{\varphi_{w}-\frac{1}{2}}{\sqrt{2} \sigma_{1}}\right)\right.\right. \\
& \left.\left.-\operatorname{erf}\left(-\frac{\varphi_{w}+\frac{1}{2}}{\sqrt{2} \sigma_{2}}\right)\right]\right\} .
\end{aligned}
$$

Here, $\sigma_{1,2}=1 / L \sqrt{\left(\sigma_{K} / \partial H_{\text {eff }} / \partial x\right)^{2}+\sigma_{L}^{2}+\sigma_{S}^{2}}$ where $L$ is the bit spacing, $\sigma_{L}$ is the lithographic deviation in bit spacing, $\sigma_{K}$ is the switching field distribution, $\sigma_{S}$ is the write timing jitter, $\partial H_{\mathrm{eff}} / \partial x$ is the effective head field gradient, and $E_{0}$ is the max error rate. The subscripts for $\sigma$ denote which of the two mechanisms discussed above generated the write error, each of which could be governed by a different average head field gradient. The dotted lines in Fig. 2 show the fit of the OTERs using Eq. (1). The best fit $\sigma_{1}\left(\sigma_{2}\right)$ is $0.056(0.083), 0.075$ $(0.080)$, and $0.096(0.066) \pm 0.05$ for 100,200 , and $320 \mathrm{~Gb} / \mathrm{in}^{2}$, respectively. The $\sigma$ values are consistent with our measured values of $\sigma_{K}(1.0 \mathrm{kOe})$ and $\sigma_{L}(1 \mathrm{~nm})$ if we assume a reasonable head field gradient of $300 \mathrm{Oe} / \mathrm{nm}$. The uncorrelated write jitter is below $1 \mathrm{~nm}$ and we do not include it in this estimation. The best fit values of $E_{0}$ are $10 \%$ lower than the expected $0.25,{ }^{2}$ which suggests that the accuracy for determining $\varphi_{\mathrm{w}}$ during the write process is around $0.05 \mathrm{~L}$.

In conclusion, we have measured the intrinsic bit error rate dependence on track misregistration for BPM at densities of $100-320 \mathrm{~Gb} / \mathrm{in}^{2}$. We have demonstrated sub $10^{-4}$ two-dimensional BER recording at 100 and $200 \mathrm{~Gb} / \mathrm{in}^{2}$ and $10^{-3} \mathrm{BER}$ recording at $320 \mathrm{~Gb} / \mathrm{in}^{2}$. The dependence of the OTER on the write phase is well-described by a model that matches the measured physical parameters of our system. Our results show promise for future BPM technology, though much works remains in optimizing fabrication processes, media properties, and head parameters.

${ }^{1}$ B. D. Terris and T. Thomson, J. Phys. D: Appl. Phys. 38, R199 (2005); T. R. Albrecht, O. Hellwig, R. Ruiz, M. E. Schabes, B. D. Terris, and X. Wu, in Nanoscale Magnetic Materials and Applications, edited by J. P. Liu, E. Fullerton, O. Gutfleisch, and D. J. Sellmyer (Springer, Dordrecht, 2009), pp. 237-274.

${ }^{2}$ H. J. Richter, A. Y. Dobin, O. Heinonen, K. Z. Gao, R. J. M. Van der Veerdonk, R. T. Lynch, J. Xue, D. Weller, P. Asselin, M. F. Erden, and R. M. Brockie, IEEE Trans. Magn. 42, 2255 (2006); H. J. Richter, A. Y. Dobin, R. T. Lynch, D. Weller, R. M. Brockie, O. Heinonen, K. Z. Gao, J. Xue, R. J. M. van der Veerdonk, P. Asselin, and M. F. Erden, Appl. Phys. Lett. 88, 222512 (2006); M. E. Schabes, J. Magn. Magn. Mater. 320, 2880 (2008).

${ }^{3}$ M. Albrecht, A. Moser, C. T. Rettner, S. Anders, T. Thomson, and B. D. Terris, Appl. Phys. Lett. 80, 3409 (2002); M. Albrecht, C. T. Rettner, A. Moser, M. E. Best, and B. D. Terris, ibid. 81, 2875 (2002); A. Moser, O. Hellwig, D. Kercher, and E. Dobisz, ibid. 91, 162502 (2007); A. Kikitsu, J. Magn. Magn. Mater. 321, 526 (2009).

${ }^{4}$ H. Suzuki, W. C. Messner, J. A. Bain, V. Bhagavatula, and S. Nabavi, IEEE Trans. Magn. 45, 3749 (2009).

${ }^{5}$ Y. J. Chen, T. L. Huang, S. H. Leong, S. B. Hu, K. W. Ng, Z. M. Yuan, B. Y. Zong, B. Liu, and V. Ng, Appl. Phys. Lett. 93, 102501 (2008).

${ }^{6}$ Y. Tang, K. Moon, and H. J. Lee, IEEE Trans. Magn. 45, 822 (2009).

${ }^{7}$ M. Todorovic, S. Schultz, J. Wong, and A. Scherer, Appl. Phys. Lett. 74, 2516 (1999); M. Albrecht, S. Ganesan, C. T. Rettner, A. Moser, M. E. Best, R. L. White, and B. D. Terris, IEEE Trans. Magn. 39, 2323 (2003); N. Yasui, S. Ichihara, T. Nakamura, A. Imada, T. Saito, Y. Ohashi, T. Den, K. Miura and H. Muraoka, J. Appl. Phys. 103, 07 C515 (2008); J. Moritz, L. Buda, B. Dieny, J. P. Nozieres, R. J. M. van de Veerdonk, T. M. Crawford, and D. Weller, Appl. Phys. Lett. 84, 1519 (2004); G. Hu, T. Thomson, M. Albrecht, M. E. Best, B. D. Terris, C. T. Rettner, S. Raoux, G. M. McClelland, and M. W. Hart, J. Appl. Phys. 95, 7013 (2004).

${ }^{8}$ R. Wood, M. Williams, A. Kavcic, and J. Miles, IEEE Trans. Magn. 45, 917 (2009).

${ }^{9}$ S. Landis, B. Rodmacq, B. Dieny, B. Dal'Zotto, S. Tedesco, and M. Heitzmann, Appl. Phys. Lett. 75, 2473 (1999); O. Hellwig, A. Berger, T. Thomson, E. Dobisz, Z. Z. Bandic, H. Yang, D. S. Kercher, and E. E. Fullerton, ibid. 90, 162516 (2007); T. Hauet, E. Dobisz, S. Florez, J. Park, B. Lengsfield, B. D. Terris, and O. Hellwig, ibid. 95, 262504 (2009).

${ }^{10}$ O. Hellwig, A. Moser, E. Dobisz, Z. Z. Bandic, H. Yang, D. S. Kercher, J. D. Risner-Jamtgaard, D. Yaney, and E. E. Fullerton, Appl. Phys. Lett. 93, 192501 (2008).

${ }^{11}$ A. Moser, D. Weller, M. E. Best, and M. F. Doerner, J. Appl. Phys. 85, 5018 (1999). 